\title{
Spore Acquisition and Survival of Ambrosia Beetles Associated with the Laurel Wilt Pathogen in Avocados after Exposure to Entomopathogenic Fungi
}

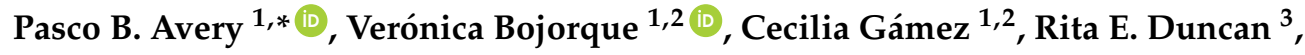 \\ Daniel Carrillo $^{3}$ and Ronald D. Cave ${ }^{1}$ \\ 1 Indian River Research and Education Center, IFAS, University of Florida, 2199 South Rock Road, Ft. Pierce, \\ FL 34945, USA; veroboj@hotmail.com (V.B.); cgam.h@hotmail.com (C.G.); rdcave@ufl.edu (R.D.C.) \\ 2 Escuela Agrícola Panamericana, P.O. Box 93 Tegucigalpa, Honduras \\ 3 Tropical Research and Education Center, IFAS, University of Florida, Homestead, FL 33031, USA; \\ ritad@ufl.edu (R.E.D.); dancar@ufl.edu (D.C.) \\ * Correspondence: pbavery@ufl.edu; Tel.: +1-772-577-7335
}

Received: 1 March 2018; Accepted: 17 April 2018; Published: 25 April 2018

\begin{abstract}
Laurel wilt is a disease threatening the avocado industry in Florida. The causative agent of the disease is a fungus vectored by ambrosia beetles that bore into the trees. Until recently, management strategies for the vectors of the laurel wilt fungus relied solely on chemical control and sanitation practices. Beneficial entomopathogenic fungi (EPF) are the most common and prevalent natural enemies of pathogen vectors. Laboratory experiments demonstrated that commercial strains of EPF can increase the mortality of the primary vector, Xyleborus glabratus, and potential alternative vectors, Xylosandrus crassiusculus, Xyleborus volvulus and Xyleborus bispinatus (Coleoptera: Curculionidae: Scolytinae). Our study provides baseline data for three formulated commercially-available entomopathogenic fungi used as potential biocontrol agents against $X$. crassiusculus, X. volvulus and X. bispinatus. The specific objectives were to determine: (1) the mean number of viable spores acquired per beetle species adult after being exposed to formulated fungal products containing different strains of EPF (Isaria fumosorosea, Metarhizium brunneum and Beauveria bassiana); and (2) the median and mean survival times using paper disk bioassays. Prior to being used in experiments, all fungal suspensions were adjusted to $2.4 \times 10^{6}$ viable spores $/ \mathrm{mL}$. The number of spores acquired by X. crassiusculus was significantly higher after exposure to B. bassiana, compared to the other fungal treatments. For $X$. volvulus, the numbers of spores acquired per beetle were significantly different amongst the different fungal treatments, and the sequence of spore acquisition rates on X. volvulus from highest to lowest was I. fumosorosea $>$ M. brunneum $>$ B. bassiana. After X. bispinatus beetles were exposed to the different suspensions, the rates of acquisition of spores per beetle amongst the different fungal treatments were similar. Survival estimates (data pooled across two tests) indicated an impact for each entomopathogenic fungus per beetle species after exposure to a filter paper disk treated at the same fungal suspension concentration. Kaplan-Meier analysis (censored at day 7) revealed that each beetle species survived significantly shorter in bioassays containing disks treated with EPF compared to water only. This study demonstrated that ambrosia beetles associated with the laurel wilt pathogen in avocados are susceptible to infection by EPF under laboratory conditions. However, the EPF needs to be tested under field conditions to confirm their efficacy against the beetles.
\end{abstract}

Keywords: ambrosia beetles; laurel wilt; avocados; entomopathogenic fungi; Kaplan-Meier analysis 


\section{Introduction}

Ambrosia beetles have symbiotic relationships with fungi that contribute to their ecological, biological and economic importance [1-3]. Ambrosia beetles associated with plant pathogenic fungi that cause diseases, such as Raffaelea lauricola T.C. Harr., Fraedrich \& Aghayeva and Fusarium spp., are becoming relevant pests for the forestry and agricultural sector in many countries [4-6]. For example, ambrosia beetles vector the fungus $R$. lauricola, which can cause laurel wilt disease in redbay, Persea borbonia (L.), silk bay, P. humilis Nash, swamp bay, P. palustris (Raf.) Spreng., and avocado, Persea americana Mill. [7-9]. Trees infected with R. lauricola are characterized by vascular discoloration, rapid wilting, defoliation, necrosis of foliage and sometimes xylem dysfunction [10]. The ability of some ambrosia beetles to act as vectors of plant pathogenic fungi in trees has brought much attention for finding management strategies that could reduce the impact of these insects.

Until recently, management strategies for ambrosia beetles in avocados have relied primarily and intensively on spraying broad-spectrum chemical insecticides, but with limited success, especially when targeting beetles that were already inside the tree [11]. Biological control using entomopathogenic fungi has been successful for managing bark beetle pests of economic importance worldwide and could also play a relevant role in the management of ambrosia beetles in avocados, as well [12-16]. Carrillo et al. [15] found that the fungal product BotaniGard ${ }^{\circledR}$ ES containing the entomopathogenic fungus Beauveria bassiana (Balsamo) had the highest efficacy and percentage mycosis compared to other fungal products tested against the red bay ambrosia beetle, Xyleborus glabratus Eichhoff, under laboratory conditions. At the time this research was conducted, it was assumed that X. glabratus was the only vector carrying $R$. lauricola to the avocados [17]; however, after further research and observations in the field, Carrillo et al. [18] found that X. glabratus is rare in commercial avocado crops. By contrast, several species of ambrosia beetles are associated with $R$. lauricola in avocado production systems. Xyleborus volvulus (Fabricius, 1775) and Xyleborus bispinatus Eichhoff (formerly recognized as X. ferrugineus (Fabricius) [19]) were demonstrated capable of transmitting the pathogen to healthy avocado trees [8,9]. The ambrosia beetle Xylosandrus crassiusculus (Motschulsky) has also been found carrying the pathogen in its mycangial pouches and attacking avocado trees [9]. Therefore, this species is still considered a potential vector of the laurel wilt disease pathogen, although it has not yet been confirmed.

The objective of our study was to create baseline data for three commercially-formulated entomopathogenic fungi that may be used as potential biocontrol agents against X. crassiusculus, $X$. volvulus and $X$. bispinatus. The specific objectives were to parameterize: (1) the number of viable spores acquired per beetle species and (2) the median and mean survival times of X. crassiusculus, $X$. volvulus and $X$. bispinatus adults after exposure to formulated fungal products containing different strains of the entomopathogenic fungi Isaria fumosorosea (Wize), Metarhizium brunneum (Petch) and B. bassiana in paper disk bioassays.

\section{Materials and Methods}

\subsection{Beetles}

Adults of $X$. bispinatus were obtained from a laboratory colony maintained following the procedures described by Menocal et al. [20]. Adults of X. crassiusculus and X. volvulus were obtained from infested avocado trees as described by Carrillo et al. [15]. Collected female beetles that emerged from the wood were collected daily and placed inside the Petri dishes ( $5 \mathrm{~cm}$ diameter) provided with a moistened filter paper, and the lid was closed, forming a chamber. Closed dish chambers containing the beetles were then sealed with Parafilm ${ }^{\circledR}$ (Bemis Co., Inc., Neenah, WI, USA) and transported overnight to the University of Florida, Indian River Research and Education Center at Fort Pierce, Florida. Upon arrival, dishes were immediately unsealed, lids briefly opened ( $30 \mathrm{~s})$ and closed and then placed on the laboratory bench for $\sim 2-3 \mathrm{~h}$. This procedure allowed the beetle's time to acclimate 
to room temperature before being used in the bioassays. All adult females in the bioassays were used within 2 days of collection.

\subsection{Fungi}

One commercial strain of $M$. brunneum (Met52 ${ }^{\circledR} \mathrm{EC}$ ) isolated from the codling moth, Cydia pomonella (L.) (J. Leland, personal communication, Novozymes Biologicals, Inc., Salem, VA, USA), one commercial strain of $I$. fumosorosea (PFR-97 ${ }^{\circledR}$ 20\% WDG) isolated from the mealybug Phenacoccus solani Ferris in Apopka, FL (Certis USA, Columbia, MD, USA) and one commercial strain of B. bassiana GHA (BotaniGard ${ }^{\circledR}$ ES, Laverlam International, Butte, MT, USA) were tested. All products were refrigerated at $4{ }^{\circ} \mathrm{C}$ until needed for experiments.

\subsection{Determining Fungal Suspension Spore Density and Viability}

The PFR-97 suspension was prepared by mixing $1 \mathrm{~g}$ of the blastospore-containing powder in $100 \mathrm{~mL}$ of sterile distilled water, stirring with a magnetic bar for $30 \mathrm{~min}$ and then letting the inert material precipitate for an additional $30 \mathrm{~min}$, leaving the supernatant containing the blastospores. Both BotaniGard ES and Met52 EC conidial suspensions were each prepared by mixing $1 \mathrm{~mL}$ of the oil-emersion liquid product in $100 \mathrm{~mL}$ of distilled water and stirring the conidial suspension with a magnetic bar for $15 \mathrm{~min}$. All conidial or blastospore suspension densities were measured by using a plastic disposable C-Chip Neubauer Improved hemocytometer (Incyto DHC-NO 1, Chungnam, Korea) observed under a Leica DM500 Brightfield microscope (Leica Microsystems, Wetzlar, Germany) at $400 \times$ magnification. All fungal suspensions were adjusted to $\sim 2.4 \times 10^{6}$ blastospores or conidia $/ \mathrm{mL}$ after being diluted with distilled water using the following formula: $F_{c} \times F_{v}=S c \times S v$, where Fc $=$ final concentration, $\mathrm{Fv}=$ final volume, $\mathrm{Sc}=$ stock concentration and $\mathrm{Sv}=$ stock volume. Changing focal depth with the microscope was required to distinguish B. bassiana and M. brunneum conidia, which have conspicuous cell walls, from droplets formed after adding water to the emulsified suspension in the BotaniGard ES and Met52 EC formulation, respectively.

Viability was determined using percent germination for all strains by spreading $100 \mu \mathrm{L}$ of each suspension containing $10^{6}$ blastospores or conidia/mL on Petri dishes containing potato dextrose agar (PDA) with streptomycin (0.5\%) added. Dishes were sealed with Parafilm ${ }^{\circledR}$, transferred to the growth chamber and incubated at $25^{\circ} \mathrm{C}$ for $18-24 \mathrm{~h}$ under a 14-h photophase. Percentage germination per fungal strain was determined by observing 100 spores in two different areas (200 spores/plate) using a Leica DM500 Brightfield microscope $(400 \times)$ on triplicate PDA plates. Germination was indicated once a germ tube had formed and was at least half the length of the blastospore or conidia. The number of viable spores $/ \mathrm{mL}$ was determined using the following formula:

Number of viable spores $/ \mathrm{mL}=$ total number of spores $/ \mathrm{mL} \times \%$ germination,

where $\%$ germination $=$ number of spores germinated $/ 200$ total spores counted per plate $\times 100$.

\subsection{Determining the Acquisition of Spores by Each Beetle Species per Fungal Suspension}

Ten adult beetles of each species were tested per fungal strain per treatment. Beetles were placed individually in a single well of a sterile polystyrene 12 -well Costar ${ }^{\circledR}$ cell culture cluster plate (Corning Inc., Corning, NY, USA), containing $0.5 \mathrm{~mL}$ of either blastospore or conidial fungal suspensions $\left(\sim 2.4 \times 10^{6}\right.$ viable spores $\left./ \mathrm{mL}\right)$, for $1-2 \mathrm{~min}$ to become contaminated. Contaminated beetles were then placed individually in Eppendorf tubes $(1.5 \mathrm{~mL})$ containing $200 \mu \mathrm{L}$ of Triton X-100 and vortexed for $15 \mathrm{~s}$. After being vortexed, one aliquot $(10 \mu \mathrm{L})$ of each suspension was placed in the C-Chip hemocytometer, and the mean number of viable spores $/ \mathrm{mL}$ per beetle was determined as described above. Beetles placed in water only, vortexed and then spores counted as above served as a control. Five beetles were used per treatment, and the experiment was conducted twice. 


\subsection{Filter Paper Disk Bioassays Chambers and Survival Assessment}

Bioassay chambers used in this experiment consisted of polystyrene plastic vials (88 oz: $11 / 16^{\prime \prime}$ $\varnothing \times 23 / 16^{\prime \prime}$, Tap Plastics ${ }^{\circledR}$, San Leandro, CA, USA) that contained a moistened filter paper disk (15 mm Ø). A 1-cm Ø hole was cut in the snap cap and a piece of cotton rope inserted, both for ventilation, as well as for maintaining additional moisture inside the vial.

The filter paper disk inside each vial prior to exposure to the beetle was contaminated with $100 \mu \mathrm{L}$ of one of the fungal suspensions. Disks moistened with only distilled water were used as controls. After the disks were treated, 15-25 untreated beetles of each species (number based on the availability of beetles/treatment/experiment) were immediately placed individually in the vial bioassay chambers, and the snap cap with the moistened cotton rope was replaced. All vials in a randomized block design were held upright in high density polystyrene racks incubated at $25^{\circ} \mathrm{C}$ under a 14-h photoperiod and examined every $24 \mathrm{~h}$ until all beetles died. Each cotton rope was moistened to saturation and $30 \mu \mathrm{L}$ of distilled water were added to the filter paper disk daily. Dead beetles were removed daily, surface sterilized using the procedure described by Lacey and Brooks [21] and transferred to Petri dishes containing moistened filter paper or $1.4 \%$ water agar. Dishes were sealed with Parafilm ${ }^{\circledR}$ and incubated the same as above. Beetles were examined 7-10 days post-mortem for mycosis, and the fungal phenotype was verified (Figure 1). Experiments were conducted twice.

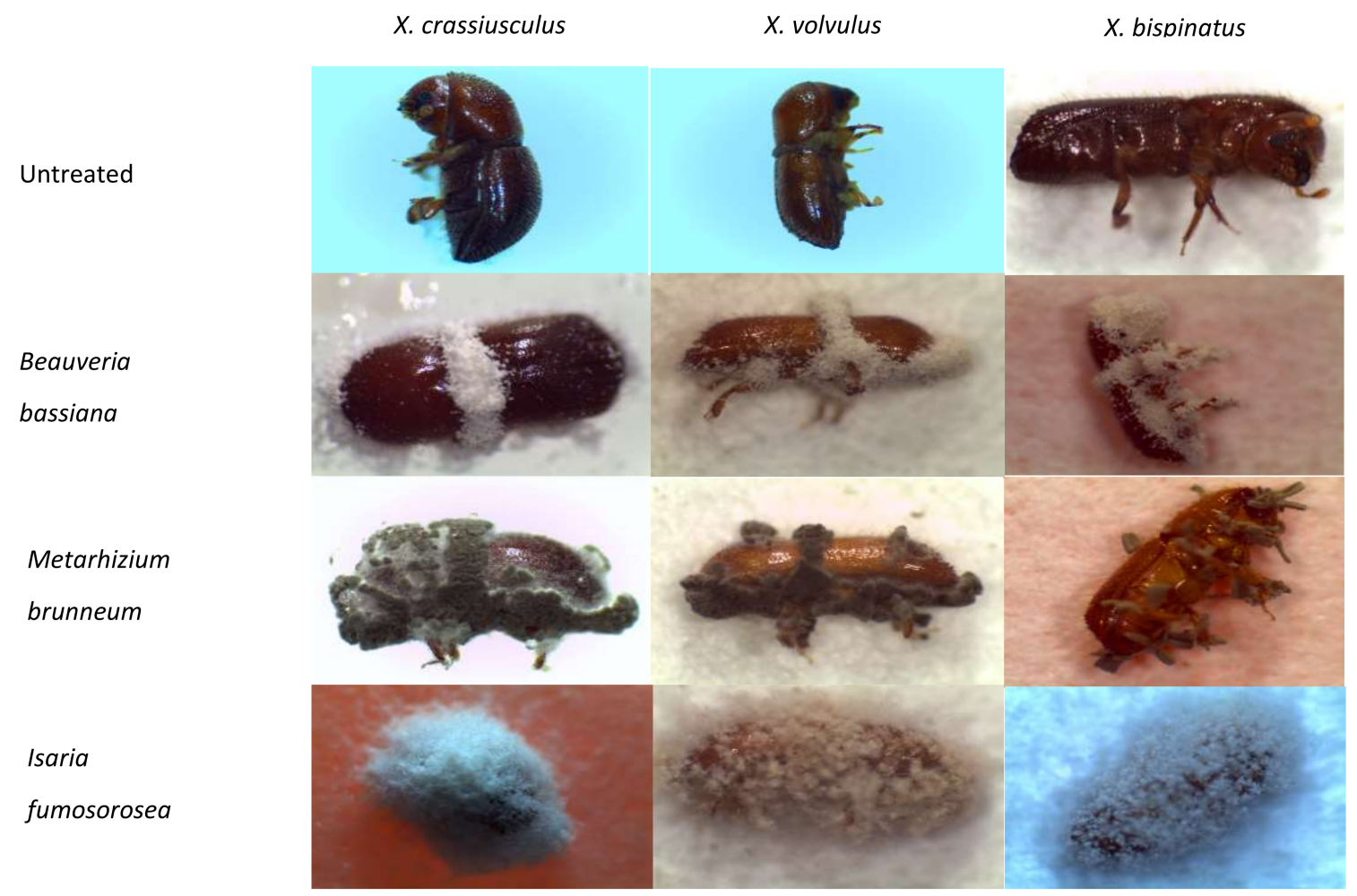

Figure 1. Comparison of untreated and mycosed Xylosandrus crassiusculus, Xyleborus volvulus and Xyleborus bispinatus after exposure to a filter paper disk inoculated with fungal suspensions $\left(2.4 \times 10^{6}\right.$ spores $\left./ \mathrm{mL}\right)$ of either Beauveria bassiana (BotaniGard ES), Metarhizium brunneum (Met52 EC), or Isaria fumosorosea (PFR-97 20\% WDG). Untreated = control disks with distilled water only. Fungal phenotype post-mortem for mycosed beetles: Beauveria bassiana with white spores; Metarhizium brunneum with green spores; Isaria fumosorosea with white to greyish mauve spores.

\subsection{Statistical Analysis}

The mean number of spores acquired and days to death for each beetle species after exposure to each fungal treatment compared to the control were statistically analyzed for significance using a 
one-way ANOVA $(p<0.05)$. If significant, treatment post hoc means were separated using Tukey's HSD test $(p<0.05)$. Statistical analyses were conducted using SAS Proc GLM procedures and executed on a PRO_WIN 6.1 platform (SAS 2002-2012; SAS Institute Inc., Cary, NC, USA). Median survival times $\left(\mathrm{ST}_{50}\right)$ were compared through Kaplan-Meier survival analysis followed by a log rank test (SAS JMP 8 for Windows 2013).

\section{Results}

\subsection{Fungal Suspension Spore Density and Viability}

Spore densities and percentages of germination adjusted to produce $2.4 \times 10^{6}$ viable spores $/ \mathrm{mL}$ for each fungal suspension are presented in Table 1. Spore densities were very similar, and the germination rate was only slightly higher for B. bassiana; however, all fungal suspensions were adjusted to $2.4 \times 10^{6}$ viable spores $/ \mathrm{mL}$ prior to use in the experiments.

Table 1. Spore densities and viabilities of three entomopathogenic fungal suspensions.

\begin{tabular}{cccc}
\hline Treatment $^{\text {a }}$ & Spores/mL $\left(\times \mathbf{1 0}^{\mathbf{6}}\right)$ & Germination $(\mathbf{\%})$ & Viable Spores/mL $\left(\times \mathbf{1 0}^{\mathbf{6}}\right)$ \\
\hline I. fumosorosea & $2.9 \pm 0.42$ & 85 & $2.4 \pm 0.36$ \\
M. brunneum & $2.8 \pm 0.27$ & 85 & $2.4 \pm 0.23$ \\
B. bassiana & $2.7 \pm 0.37$ & 89 & $2.4 \pm 0.33$ \\
\hline
\end{tabular}

\subsection{Acquisition of Spores by Each Beetle Species per Fungal Suspension}

The number of spores acquired after being dipped into a fungal suspension varied greatly among beetle species (Table 2). Spore acquisition by X. crassiusculus was significantly higher after exposure to B. bassiana, compared to the other fungal treatments. For X. volvulus, spore acquisition was highest with I. fumosorosea and lowest with B. bassiana. After X. bispinatus beetles were exposed to the different suspensions, spore acquisition per beetle did not differ significantly among the fungal treatments. None of the beetles in the control were contaminated with any of the fungal species tested.

Table 2. Comparison of the acquisition of spores by three ambrosia beetle species after being dipped into three entomopathogenic fungal suspensions ${ }^{a}$.

\begin{tabular}{|c|c|c|c|}
\hline \multirow[b]{2}{*}{ Treatment $^{b}$} & \multicolumn{3}{|c|}{ No. of Spores $\left(\times 10^{5}\right) /$ beetle $e^{c, d}$} \\
\hline & X. crassiusculus & X.volvulus & X. bispinatus \\
\hline I. fumosorosea & $4.5 \pm 0.4^{\mathrm{a}}$ & $4.5 \pm 0.4^{\mathrm{c}}$ & $0.9 \pm 1.0^{\mathrm{a}}$ \\
\hline M. brunneum & $4.0 \pm 0.4^{\mathrm{a}}$ & $2.9 \pm 0.3^{b}$ & $3.8 \pm 1.2^{\mathrm{a}}$ \\
\hline B. bassiana & $8.2 \pm 0.4^{b}$ & $1.1 \pm 0.2^{a}$ & $2.4 \pm 0.4^{\mathrm{a}}$ \\
\hline Statistical Analysis & $\begin{array}{c}F=11.3 ; \mathrm{df}=2.8 \\
p=0.0018\end{array}$ & $\begin{array}{c}F=26.2 ; \mathrm{df}=2.8 \\
p<0.0001\end{array}$ & $\begin{array}{c}F=3.35 ; \mathrm{df}=2.8 ; \\
p=0.0878\end{array}$ \\
\hline
\end{tabular}

a All fungal suspensions were adjusted to $2.4 \times 10^{6}$ spores $/ \mathrm{mL} .{ }^{\mathrm{b}}$ Isaria fumosorosea (PFR-97 20\% WDG), Metarhizium brunneum (Met52 EC), Beauveria bassiana (BotaniGard ES), control = distilled water only. ${ }^{c}$ Individual beetles were placed in an Eppendorf tube with $200 \mu \mathrm{L}$ of $0.1 \%$ Triton X-100 after being exposed to the specific fungal suspension or water and vortexed for $15 \mathrm{~s} .{ }^{\mathrm{d}}$ Values not followed by the same letter in a column are significantly different (Tukey's HSD test, $p<0.05$ ).

\subsection{Survival after Exposure to Each Fungal Treatment in a Filter Paper Disk Bioassay}

Survival rates (data pooled across both tests) indicated an impact by each entomopathogenic fungus on all beetle species after exposure to a filter paper disk treated at the same suspension concentration (Figure 2). Kaplan-Meier analysis (censored at day 7) revealed that each beetle species survived significantly longer in bioassays with disks inoculated with water only compared to 
entomopathogenic fungi, i.e., $X$. crassiusculus: $\log$ rank $X^{2}=45.0, p<0.0001, \mathrm{df}=3 ; X$. volvulus: $\log$ rank $X^{2}=13.2, p=0.0043, \mathrm{df}=3 ; X$. bispinatus: $\log \operatorname{rank} X^{2}=42.7, p<0.0001, \mathrm{df}=3$. The $\mathrm{ST}_{50}$ (days) for water only, I. fumosorosea, B. bassiana and M. brunneum treatments, respectively, after each beetle species was exposed to a paper disk for seven days, were as follows: X. crassiusculus: $5.6,4.9,4.5,5.3 ; X$. volvulus: $4.3,3.9,3.7,3.6 ; X$. bispinatus: 4.7, 4.3, 4.2, 2.9. The mean survival time for $X$. crassiusculus beetles after exposure to each fungal suspension treatment was significantly $(F=34.9 ; \mathrm{df}=3,87 ; p<0.0001)$ shorter compared to the control (water only) (Figure 2). Xylosandrus crassiusculus beetles exposed to B. bassiana died faster than when exposed to M. brunneum; however, days survival for I. fumosorosea were similar to both B. bassiana and M. brunneum. For X. volvulus, mean survival times were significantly $(F=4.36$; $\mathrm{df}=3,147 ; p=0.0057$ ) shorter for beetles exposed to $M$. brunneum and B. bassiana compared to water only; survival time of beetles exposed to I. fumosorosea were similar to the other treatments and control. The mean survival time of $X$. bispinatus beetles exposed to M. brunneum was significantly $(F=63.1$; $\mathrm{df}=3,117 ; p<0.0001$ ) shorter than that of beetles exposed to I. fumosorosea and M. brunneum; mean survival time in the control was significantly longer than in the fungal treatments.

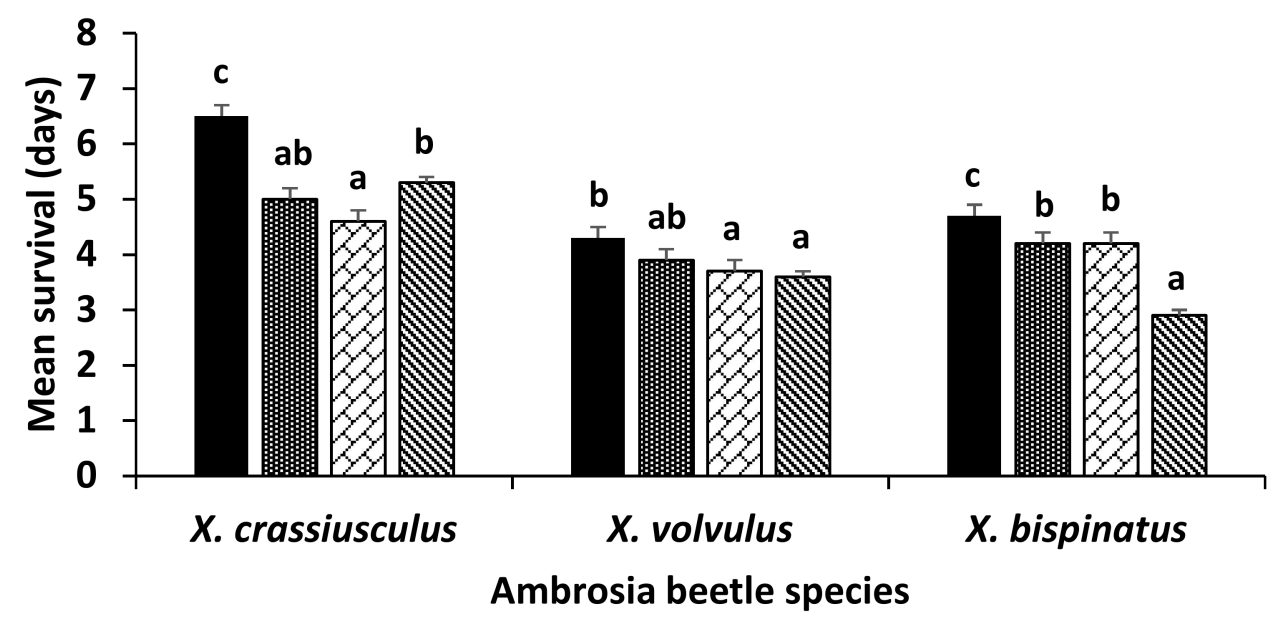

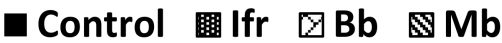

Figure 2. Comparison of the mean ( \pm SEM) days of survival for Xylosandrus crassiusculus ( $n=30$ per treatment), Xyleborus volvulus $(n=50$ per treatment) and Xyleborus bispinatus ( $n=40$ per treatment) after exposure to a filter paper disk treated with $100 \mu \mathrm{L}$ of one of three fungal suspensions $\left(2.4 \times 10^{6}\right.$ spores $\left./ \mathrm{mL}\right)$ or distilled water for seven days. Control = distilled water only, Ifr = Isaria fumosorosea (PFR-97 20\% WDG), Bb = Beauveria bassiana (BotaniGard ES), Mb = Metarhizium brunneum (Met52 EC). Bars for each beetle species not followed by the same letter are significantly different (Tukey's HSD test, $p<0.05$ ).

\section{Discussion}

This study demonstrated the efficacy of entomopathogenic fungi (EPF) against adult X. bispinatus and $X$. volvulus and assessed their actual dose delivered by immersion. In addition, this study adds further support to the original finding that X. glabratus and the three ambrosia beetles tested in this study are susceptible to the same entomopathogenic fungal biopesticides that are commercially available nationwide for avocado growers to use in their pest management programs.

Adult ambrosia beetles seemingly vary considerably in their ability to acquire the different types of spores suspended in the formulated biopesticide products. In our study, the number of acquired spores per X. bispinatus adult was similar amongst the three fungal treatments. In contrast, X. volvulus and $X$. crassiusculus acquisition did differ significantly among the fungal products. This variation in spore acquisition per beetle may be related to the morphological differences of each species and therefore cannot be compared across species due to their size and setal density differences. This hypothesis 
was not the focus of our study and cannot be confirmed from the results of this study, because the number of spores per $\mathrm{mm}^{2}$ area of the cuticle was not determined, and would require further research. In our study, the differences in spore acquisition may also be related to the type of propagule and the formulation of the fungal product.

Carrillo et al. [15] found that the number of spores acquired by X. glabratus after being dipped in the same fungal products also varied significantly. They suggested that the variance in the number of spores acquired per beetle species may also be due to the adult's physicochemical surface properties of its cuticle, as well as the fungal propagules. The insect cuticle is typically hydrophobic [22], and the adhesion of the fungal propagule, i.e., conidia or blastospore, is determined primarily by hydrophobic interactions on the surface [23]. Both BotaniGard and Met52 contain aerial conidia that are hydrophobic [24,25], and PFR-97 contains blastospores that are hydrophilic [26]. The hydrophobic conidia initially have greater non-specific binding to the hydrophobic cuticle than the hydrophilic blastospores [27]. However, due to the hydrophobic properties of B. bassiana and M. brunneum conidia compared to the hydrophilic properties of the I. fumosorosea blastospores on the beetle surface, it is possible that after washing the spores off of the beetle surface using the surfactant Triton X-100 $(0.01 \% v / v)$ that this procedure may not have removed all the blastospores adhering to the beetle cuticle, which may account for variations in the number of spores recovered for PFR-97 treatments compared to BotaniGard and Met52 from some of the beetle species. This hypothesis still warrants more research, especially with reference to the effect of hydrophilic properties and the adherence of I. fumosorosea blastospores to the insect cuticle when using this washing technique for removing blastospores from the insect cuticle.

For the control, distilled water was used only, which is a realistic control to assess the efficacy of PFR-97 (I. fumosorosea), which is a dry desiccation-tolerant blastospore-formulated powder with no surfactants or emulsifiers added to the formulation. When PFR-97 is mixed in water, the spores will suspend immediately in the supernatant; however, this is not the case for BotaniGard ES (B. bassiana) or Met52 EC (M. brunneum). Both of these conidial formulated fungal products contain a proprietary mixture of surfactants and emulsifiers suspended in oil that allows the spores to suspend when mixed in water. Therefore, in future bioassays, water only and the resultant supernatant minus the spores would be a more appropriate control when assessing the efficacy of these commercially-formulated fungal products.

Adult beetles in our study using the paper disk bioassay technique were exposed to the formulated fungal products in two ways, either indirectly by residual contact or directly by per os inoculation, i.e., ingesting or acquiring the spores while chewing the inoculated disk. All of the adult beetles chewed on the paper disk in the bioassay chamber and had the opportunity to obtain spores per os, as well as acquire spores on their body parts as they roamed on the inoculated disk. Fernandez et al. [28] observed that the second instar of the Colorado potato beetle, Leptinotarsa decemlineata (Say), acquired a high density of B. bassiana conidia on the legs, mouthparts and ventral surface areas when roaming on sprayed potato foliage. Although the Colorado potato beetle larva was contaminated, they suggested that mortality probably occurred because of infection through the cuticle of the beetle and not by ingesting $B$. bassiana conidia while feeding on the leaf surface. Therefore, in our study, the adherence of propagules obtained from the spore residue on the paper disk may have played a significant role in mortality and its efficacy may be directly related to the formulation specifics of each of the fungal products. Although speculative, this hypothesis warrants further research to elucidate the role that each inoculation process may play in the overall mortality of the different adult ambrosia beetle species.

In our study, the mean survival of the different ambrosia beetle species per formulation varied similarly to that of their spore acquisition. Beetles exposed to the disks inoculated with B. bassiana and M. brunneum died significantly faster than those with I. fumosorosea. As stated above, BotaniGard and Met52 are both oil/emulsifier-formulated, and PFR-97 is a blastospore powder-type product. The $B$. bassiana and $M$. brunneum treatments, when applied in oil-in-water emulsion, will have conidia generally surrounded by oil droplets, which may enhance their adherence to the insect 
cuticle. Prior et al. [29] demonstrated that B. bassiana conidia in an oil-based formulation adhered significantly better to the cuticle of the cocoa weevil, Pantorhytes plutus (Oberthür), and enhanced higher mortality with a lower lethal time value compared to the water formulation. Under laboratory and field conditions, Batta [30] demonstrated a significantly higher level of efficacy with formulated B. bassiana conidia in an emulsion compared to no emulsion against the almond bark beetle, Scolytus amygdali Guérin-Méneville. In another study, Carrillo et al. [15], using the same paper disk bioassay technique described above at the same suspension concentration per fungal product, found that the oil/emulsifier-formulated BotaniGard and Met52 had a higher mortality compared to the I. fumosorosea blastospore-powder formulated PFR-97 product and water only. Overall, oil-based formulations of fungal conidial biopesticides have been reported to increase the adherence of propagules to the insect integument by: (1) enhancing the spread of the inoculum and subsequent penetration of the insect cuticle, (2) protecting propagules from ultraviolet light radiation and (3) enhancing infection under low humidity [31]. Factors that may inhibit or enhance germination and penetration include cuticle density or compounds on the insect integument [32,33]. In addition, the lack of nutrients on sclerotized beetle cuticle is a limiting factor in fungal growth and development [34]. Other physical or chemical aspects defining the interactions at the cuticle barrier between the entomopathogenic fungus and insect that ultimately can lead to either successful mycosis by the entomopathogen or successful defense by the host have been extensively reviewed [35]. Our data suggest that the formulation of each EPF can affect the adherence of spores to beetles, which could have a subsequent positive effect on reducing the spread of $R$. lauricola. Considering that these bioassays were conducted under optimum laboratory conditions, the apparent positive effect of the conidial oil-based formulations remains to be confirmed under field conditions.

The ambrosia beetle species that are vectors of $R$. lauricola are morphologically different, but their reproductive behavior should be similar to that of X. glabratus. Ideally, EPF treatments could prevent ambrosia beetles from boring into the trees, thereby potentially eliminating the risk of $R$. lauricola transmission. However, Carrillo et al. [15] found that that X. glabratus females were able to bore into avocado log bolts and construct galleries regardless of the fungal treatment. Carrillo et al. [15] also observed that even if the EPF-infected beetle bores into the tree, the mycosed insect inside the tree will kill the next-generation brood. Brar et al. [36] observed that X. glabratus females excavate a primary gallery that can branch into secondary and tertiary galleries where eggs are laid, $\sim 7$ days after gallery initiation. The median and mean survival times of $X$. glabratus and the other ambrosia beetle females in our study exposed to EPF ranged from 3-5 days based on a dose of $2.4 \times 10^{6}$ spores $/ \mathrm{mL}$. This spore concentration tested under laboratory conditions is much lower compared to a typical rate applied in the field (e.g., $8.8 \times 10^{7}$ spores $/ \mathrm{mL}$ for BotaniGard ES), yet it provided efficacious mortality. Although all tested fungal formulated products can prevent beetle reproduction, the most effective fungal product will be the one causing the highest beetle mortality regardless of their survivorship times. In addition, the entomopathogenic fungal infection of adult ambrosia beetle females could potentially suppress the growth or establishment of their fungal symbionts in the galleries that become contaminated with entomopathogenic and saprophytic organisms associated with the beetle cadavers. Results from laboratory competition in vitro studies indicate that the biofungicide product RootShield ${ }^{\circledR} \mathrm{Plus}^{+} \mathrm{WP}$, containing Trichoderma harzianum Rifai and T. virens (J.H. Mill., Giddens \& A.A. Foster), can inhibit the radial hyphal growth of $R$. lauricola (P. Avery, unpublished data). Perhaps, this biofungicidal product could be applied on the trunk of the avocado trees along with the EPF and potentially reduce the spread of $R$. lauricola in the groves. This promising strategy warrants much more research for determining the most efficacious application of the selected biopesticides under laboratory and then field conditions.

In our experiments, beetles were offered the inoculated paper disk in a no-choice condition and exposed to EPF over time. This same paper disk bioassay technique was used by Carrillo et al. [15] for testing the same EPF against X. glabratus which resulted in similar findings to our study. Although our findings using this technique showed significant differences among treatments and the control, 
the short mean longevity of beetles in the controls ( $~ 7-8$ days) and relatedness to the natural conditions in the field were a concern when assessing the efficacy of these fungal products. The poor survival of $X$. volvulus and X. bispinatus beetles could be attributed to the fact that the inoculated paper disk in each vial did not remain as moist throughout the day as those with the $X$. crassiusculus beetles. During the bioassay trials with $X$. crassiusculus beetles, the inoculated disks were watered twice a day, whereas the disks that the $X$. volvulus and X. bispinatus beetles were exposed to were watered once due to the lack of labor availability. Therefore, due to the concern noted above, an improved avocado bark plug bioassay is being designed for exposing the beetles to each fungal product under semi-natural field conditions (P. Avery, personal communication).

Due to the similarity of the life histories and behavior of X. crassiusculus, $X$. volvulus and $X$. bispinatus to X. glabratus, we will use X. glabratus as a model system because it has been studied extensively compared to the other beetles [36]. The model system will be used to visually describe a possible scenario where using EPF as a pest management strategy can be more efficacious than just applying conventional insecticides. According to observations by Brar et al. [36], these ambrosia beetles have a unimodal dispersal peak, engaging in host-seeking flight during the late afternoon, which is directed by plant host-based volatiles, primarily sesquiterpenes [37]. Upon finding a host tree, the beetles roam on the bark of the tree trunk for relatively long periods of time $(\sim 1 \mathrm{~h}, \mathrm{D}$. Carrillo, personal observation) before boring into the trunk. During the roaming time, the beetles might be exposed to fungal spores by landing on an EPF-contaminated bait station or bark surface of a host tree prior to engaging in another host-seeking flight. Carrillo et al. [15] found high infection rates in beetles interacting with wood treated with the different fungi and suggested that trunk sprays or bait stations where the beetles land and interact with a fungus-treated surface could act as delivery and auto-dissemination systems. Improving the delivery system of fungal strains could result in increased mortality rates of ambrosia beetle females.

Xyleborus volvulus and X. bispinatus are confirmed vectors of $R$. lauricola that can kill an avocado tree by the inoculation of a few spores. This transmission of the pathogen definitely increases the challenge of achieving an integrated pest management approach and thereby the probability that conventional insecticides will need to be applied often by avocado growers. The current pest management strategy is based on early detection and removal of diseased trees to eliminate beetle breeding sites and fungal inoculum sources. The diseased trees are uprooted, stump and roots burned, the trunk and limbs chipped and the chips and adjacent trees sprayed with synthetic insecticides. Our results suggest that applications of EPF, in combination with other management tactics, including the use of compatible conventional pesticides, might suppress beetle populations that vector $R$. lauricola to avocados and mitigate the adverse effects of this beetle-disease complex. In another study, work is ongoing to determine the conventional agrochemicals commonly used by growers that are compatible with the commercially-available fungal biopesticides containing EPF, which can be applied together for management of the ambrosia beetles vectoring $R$. lauricola to avocado trees.

\section{Conclusions}

In field experiments, Carrillo et al. [15] revealed that EPF do not prevent X. glabratus beetles from boring into the trees; however, the EPF-infected beetles die inside the trees and mycose without reproducing. Therefore, the EPF may provide control similar to that by chemical insecticides, but persist longer on the bark of avocado trees and will potentially cause epizootics under the proper environmental conditions. Our study demonstrated that other ambrosia beetle vectors of $R$. lauricola that have been observed on the avocados are also susceptible to infection by EPF and should be able to be managed effectively. Therefore, to improve field efficacy, EPF must be integrated into the management strategy for $R$. lauricola and other avocado pests, which includes the use of several fungicides, insecticides and adjuvants. In another study, we are determining antagonistic and synergistic relationships among EPF and agrochemicals used by avocado growers. Several producers have incorporated this biocontrol strategy to manage ambrosia beetles and other pests of avocado, 
but the main limitation of EPF is they do not control ambrosia beetles already breeding inside the trees. Therefore, the search for improved delivery systems that could increase the efficacy of EPF, as well as the integration of biofungicides for reducing the spread of laurel wilt disease is still ongoing.

Author Contributions: Conceived and designed the experiments: P.B.A., V.B. and D.C. Performed the experiments: P.B.A., V.B. and C.G. Analyzed the data: P.B.A. Contributed materials/analysis tools: R.E.D., R.D.C. and D.C. Wrote the paper: P.B.A., V.B. and D.C. All authors participated in manuscript revisions and in making the final approval of the manuscript version submitted for publication.

Acknowledgments: We are grateful to Julio Mantilla for providing the ambrosia beetles. Mention of any trade names or products does not imply endorsement or recommendation by the University of Florida. This research was supported by grants from the United States Department of Agriculture/Florida Department of Agriculture and Consumer Services (FDACS) Specialty Crop Block Grant Program and FDACS, Division of Plant Industry Contracts \#023513 and \#024409.

Conflicts of Interest: The authors declare no conflict of interest.

\section{References}

1. Beaver, R.A. Insect-Fungus relationships in the bark and ambrosia beetles. In Insect-Fungus Interactions; Wilding, N., Collins, N.M., Hammond, P., Webber, J.F., Eds.; Elsevier Ltd.: London, UK, 1989; pp. 121-137.

2. Rudinsky, J.A. Ecology of Scolytidae. Ann. Rev. Entomol. 1962, 7, 327-348. [CrossRef]

3. Six, D.L. Ecological and evolutionary determinants of bark beetle-fungus symbioses. Insects 2012, 3, 339-366. [CrossRef] [PubMed]

4. Harrington, T.C.; Fraedrich, S.W.; Aghayeva, D.N. Raffaelea lauricola, a new ambrosia beetle symbiont and pathogen on the Lauraceae. Mycotaxon 2008, 104, 399-404.

5. Hulcr, J.; Mann, R.; Stelinski, L.L. The scent of a partner: Ambrosia beetles are attracted to volatiles from their fungal symbionts. J. Chem. Ecol. 2011, 12, 1374-1377. [CrossRef] [PubMed]

6. O’Donnell, K.; Sink, S.; Libeskind-Hadas, R.; Hulcr, J.; Kasson, M.T.; Ploetz, R.C.; Joshua, L.; Konkol, J.L.; Ploetz, J.N.; Carrillo, D.; et al. Discordant phylogenies suggest repeated host shifts in the Fusarium-Euwallacea ambrosia beetle mutualism. Fungal Genet. Biol. 2015, 82, 277-290. [CrossRef] [PubMed]

7. Fraedrich, S.W.; Harrington, T.C.; Rabaglia, R.J. Laurel Wilt: A New and Devastating Disease of Redbay Caused by a Fungal Symbiont of the Exotic Redbay Ambrosia Beetle. Available online: http:/ /www.public. iastate.edu/ tcharrin/NewsMich.pdf (accessed on 6 November 2017).

8. Carrillo, D.; Duncan, R.E.; Ploetz, J.N.; Campbell, A.F.; Ploetz, R.C.; Peña, J.E. Lateral transfer of a phytopathogenic symbiont among native and exotic ambrosia beetles. Plant Pathol. 2014, 63, 54-62. [CrossRef]

9. Ploetz, R.C.; Konkol, J.L.; Narvaez, T.; Duncan, R.E.; Saucedo, R.J.; Campbell, A.; Mantilla, J.; Carrillo, D.; Kendra, P.E. Presence and prevalence of Raffaelea lauricola, cause of laurel wilt, in different species of ambrosia beetle in Florida, USA. J. Econ. Entomol. 2017, 110, 347-354. [PubMed]

10. Inch, S.A.; Ploetz, R.C. Impact of laurel wilt, caused by Raffaelea lauricola, on xylem function in avocado, Persea americana. For. Pathol. 2012, 42, 239-245. [CrossRef]

11. Carrillo, D.; Crane, J.H.; Peña, J.E. Potential of contact insecticides to control Xyleborus glabratus (Coleoptera: Curculionidae), a vector of laurel wilt disease in avocados. J. Econ. Entomol. 2013, 106, 2286-2295. [CrossRef] [PubMed]

12. Castrillo, L.A.; Griggs, M.H.; Ranger, C.M.; Reding, M.E.; Vandenberg, J.D. Virulence of commercial strains of Beauveria bassiana and Metarhizium brunneum (Ascomycota: Hypocreales) against adult Xylosandrus germanus (Coleoptera: Curculionidae) and impact on brood. Biol. Control 2011, 58, 121-126. [CrossRef]

13. Ansaria, M.A.; Butt, T.M. Susceptibility of different developmental stages of large pine weevil Hylobius abietis (Coleoptera: Curculionidae) to entomopathogenic fungi and effect of fungal infection to adult weevils by formulation and application methods. J. Invertebr. Pathol. 2012, 111, 33-40. [CrossRef] [PubMed]

14. Castrillo, L.A.; Griggs, M.H.; Vandenberg, J.D. Granulate ambrosia beetle, Xylosandrus crassiusculus (Coleoptera: Curculionidae), survival and brood production following exposure to entomopathogenic and mycoparasitic fungi. Biol. Control 2013, 67, 220-226. [CrossRef] 
15. Carrillo, D.; Dunlap, C.A.; Avery, P.B.; Navarrete, J.B.; Duncan, R.E.; Jackson, M.A.; Behle, R.W.; Cave, R.D.; Crane, J.; Rooney, A.P.; et al. Entomopathogenic fungi as biological control agents of the vector of the laurel wilt disease, the redbay ambrosia beetle, Xyleborus glabratus (Coleoptera: Curculionidae). Biol. Control 2015, 81, 44-50. [CrossRef]

16. Kocaçevik, S.; Sevim, A.; Eroğlu, M.; Demirbağ, Z.; Demir, I. Virulence and horizontal transmission of Beauveria pseudobassiana S.A. Rehner \& Humber in Ips sexdentatus and Ips typographus (Coleoptera: Curculionidae). Turk. J. Agric. For. 2016, 40, 241-248.

17. Mayfield, A.E., III; Peña, J.E.; Crane, J.H.; Smith, J.A.; Branch, C.L.; Ottoson, E.D.; Hughes, M. Ability of the redbay ambrosia beetle (Coleoptera: Curculionidae: Scolytinae) to bore into young avocado (Lauraceae) plants and transmit the laurel wilt pathogen (Raffaelea sp.). Fla. Entomol. 2008, 91, 485-487. [CrossRef]

18. Carrillo, D.; Duncan, R.E.; Peña, J.E. Ambrosia beetles (Coleoptera: Curculionidae: Scolytinae) that breed in avocado wood in Florida. Fla. Entomol. 2012, 95, 573-579. [CrossRef]

19. Atkinson, T.H.; Carrillo, D.; Duncan, R.E.; Peña, J.E. Occurrence of Xyleborus bispinatus (Coleoptera: Curculionidae: Scolytinae) Eichhoff in southern Florida. Zootaxa 2013, 3669, 96-100. [CrossRef] [PubMed]

20. Menocal, O.; Cruz, L.F.; Kendra, P.E.; Crane, J.H.; Ploetz, R.C.; Carrillo, D. Rearing Xyleborus volvulus (Coleoptera: Curculionidae) on media containing sawdust from avocado or silkbay, with or without Raffaelea lauricola (Ophiostomatales: Ophiostomataceae). Environ. Entomol. 2017, 46, 1275-1283. [CrossRef] [PubMed]

21. Lacey, L.A.; Brooks, W.M. Initial handling and diagnosis of diseased insects. In Manual of Techniques in Insect Pathology; Lacey, L., Ed.; Academic Press, Inc.: San Diego, CA, USA, 1997; p. 5.

22. Vincent, J.F.V. Arthropod cuticle: A natural composite shell system. Compos. Part A Appl. Sci. Manuf. 2002, 33, 1311-1315. [CrossRef]

23. Boucias, D.G.; Pendland, J.C.; Latge, J.P. Nonspecific factors involved in attachment of entomopathogenic deuteromycetes to host insect cuticle. Appl. Environ. Microbiol. 1988, 54, 1795-1805. [PubMed]

24. Jeffs, L.B.; Xavier, I.J.; Matai, R.E.; Khachatourians, G.G. Relationships between fungal spore morphologies and surface properties for entomopathogenic members of the genera Beauveria, Metarhizium, Paecilomyces, Tolypocladium, and Verticillium. Can. J. Microbiol. 1999, 45, 936-948. [CrossRef]

25. Holder, D.J.; Kirkland, B.H.; Lewis, M.W.; Keyhani, N.O. Surface characteristics of the entomopathogenic fungus Beauveria (Cordyceps) bassiana. Microbiology 2007, 153, 3448-3457. [CrossRef] [PubMed]

26. Dunlap, C.A.; Biresaw, G.; Jackson, M.A. Hydrophobic and electrostatic cell surface properties of blastospores of the entomopathogenic fungus Paecilomyces fumosoroseus. Colloids Surf. B 2005, 46, 261-266. [CrossRef] [PubMed]

27. Van Oss, C.J. Hydrophobicity of biosurfaces-Origin, quantitative determination and interaction energies. Colloids Surf. B 1995, 5, 91-110. [CrossRef]

28. Fernandez, S.; Groden, E.; Vandenburg, J.D.; Furlong, M.J. The effect of mode of exposure to Beauveria bassiana on conidia acquisition and host mortality of Colorado potato beetle, Leptinotarsa decemlineata. J. Invertebr. Pathol. 2001, 77, 217-226. [CrossRef] [PubMed]

29. Prior, C.; Jollands, P.; Le Patourel, G. Infectivity of oil and water formulations of Beauveria bassiana (Deuteromycotina: Hyphomycetes) to the cocoa weevil pest Pantorhytes plutus (Coleoptera: Curculionidae). J. Invertebr. Pathol. 1988, 52, 66-72. [CrossRef]

30. Batta, Y.A. Biocontrol of almond bark beetle (Scolytus amygdali Guérin-Méneville, Coleoptera: Scolytidae) using Beauveria bassiana (Bals.) Vuill. (Deuteromycotina: Hyphomycetes). J. Appl. Microbiol. 2007, 103, 1406-1414. [CrossRef] [PubMed]

31. Inglis, G.D.; Jaronski, S.T.; Wraight, S.P. Use of spray oils with entomopathogens. In Spray Oils beyond 2000; Beattie, G.A.C., Watson, D.M., Eds.; Sustainable Pest and Disease Management; University of Western Sydney: Hawkesbury, Australia, 2002; pp. 302-312.

32. Woods, S.P.; Grula, E.A. Utilizable surface nutrients on Heliothis zea available for growth of Beauveria bassiana. J. Invertebr. Pathol. 1984, 43, 259-269. [CrossRef]

33. Sosa-Gomez, D.R.; Boucias, D.G.; Nation, J.L. Attachment of Metarhizium anisopliae to the southern green stink bug Nezara viridula cuticle and fungistatic effect of cuticular lipids and aldehydes. J. Invertebr. Pathol. 1997, 69, 31-39. [CrossRef] [PubMed]

34. Hunt, D.W.A.; Borden, J.H.; Rahe, J.E.; Whitney, H.S. Nutrient-mediated germination of Beauveria bassiana conidia on the integument of the bark beetle Dendroctonus ponderosae (Coleoptera: Scolytidae). J. Invertebr. Pathol. 1984, 44, 304-314. [CrossRef] 
35. Oritz-Urquiza, A.; Keyhani, N.O. Action on the surface: entomopathogenic fungi versus the insect cuticle. Insects 2013, 4, 357-374. [CrossRef] [PubMed]

36. Brar, G.S.; Capinera, J.L.; McLean, S.; Peña, J.E. Life cycle, development and culture of Xyleborus glabratus (Coleoptera: Curculionidae: Scolytinae). Fla. Entomol. 2013, 96, 1158-1167. [CrossRef]

37. Kendra, P.E.; Montgomery, W.S.; Niogret, J.; Peña, J.E.; Capinera, J.L.; Brar, G.; Epsky, N.D.; Heath, R.R. Attraction of the redbay ambrosia beetle, Xyleborus glabratus, to avocado, lychee, and essential oil lures. J. Chem. Ecol. 2011, 37, 932-942. [CrossRef] [PubMed]

(c) 2018 by the authors. Licensee MDPI, Basel, Switzerland. This article is an open access article distributed under the terms and conditions of the Creative Commons Attribution (CC BY) license (http:/ / creativecommons.org/licenses/by/4.0/). 